\title{
Development of Metric Evaluation for Sustainable University
}

\author{
Elia Syarafina Abdul Shakur, Choong Weng Wai, Khatijah Omar
}

\begin{abstract}
Awareness towards the enviroment by the university community has started since 1970 through various activities such as 'Earth Day'celebration. The aim of such activities was to make sure that the university emphasized on the sustainanble practices among the community in preserving the enviroment. The initiative to transform the local university to a sustainable university has been carried out by a number of research universities, namely; UTM, UKM, USM, UPM, and UM. This can be seen in various efforts carried out by the university such as setting up research centre solely for the enviroment; carrying out activities for sustainable university, forming sustainability policy and etc. However all these efforts would be furtile if a metric was not used to measure the level of sustainability to evaluate through practices at the university. A research has been done to develop a metric evaluation for sustainable university that has characteristics of sustainability. This research is carried out by interviewing 13 sustainability experts who are well-werse in the field of social economy and enviroment. The outcome of the research are the characteristics and sub elements of a sustainable university together with a comprehensive metric evaluation. This metric evaluation will function as a bench mark to observe the initiative level of sustainability at UTM as well as other local universities. This metric would guide universities to assess the level of sustainability of the university.
\end{abstract}

Keywords: Metric evaluation, Sustainability, Sustainable University.

\section{INTRODUCTION}

University is a place where activities and programs are carried out to bring awareness towards the environmental. Activities carried out at the university will give an impact directly or indirectly to the environment and its sustainability. This would in turn enables the university introduce the concept of sustainability to its staff and students. The importance of a sustainable university is to understand the interaction between human and the environment and how the environment is managed wisely and responsibly towards a sustainable life. UTM is promoting sustainable development by integrating the concept into its vision and mission to achieve its aim of a 'sustainable campus'. However, the

Revised Manuscript Received on December 22, 2018.

* Correspondence Author

Dr. Elia Syarafina Abdul Shakur, Institute of Tropical Biodiversity \& Sustainable Development, Universiti Malaysia Terengganu, 21030 Kuala Nerus, Terengganu, Malaysia and ${ }^{\mathrm{b}}$ Fakulti Alam Bina dan Ukur, Universiti Teknologi Malaysia, 81310 UTM Johor Bahru, Johor, Malaysia. Email: eliasya@umt.edu.my

Assoc. Prof. Sr. Dr. Choong Weng Wai, Faculty of Built Environment and Surveying, Universiti Teknologi Malaysia, 81310 UTM Johor Bahru, Johor, Malaysia. Email: cwengwai@utm.my

Assoc. Prof. Dr. Khatijah Omar, Faculty of Business, Economics and Social Development / and Institute of Tropical Biodiversity \& Sustainable Development, Universiti Malaysia Terengganu, Malaysia. Email: khatijah@umt.edu.my challenges faced are the changes in the university role and responsibility to develop sustainability.

The university would find it difficult to carry out its social responsibility towards a community which lacks a sustainable mind. According to Zaini [24], sustainable mind is the thinking, the soul and the lifestyle of a community that has been influenced by the awareness, the realization and the feelings of responsibility that has been developed freely. It is a combination of mind, emotion, practices and culture.

UTM has taken a few steps to achieve the status of a sustainable university. However, UTM authorities should have strategies to overcome the above mentioned challenges. Besides, it would be difficult to overcome these challenges if there is no evaluation to decide the characteriscs of a sustainable university.

Harrington [7], stated that evaluation is the first step to control and eventually to upgrade anything. If evaluation is not done, it would be difficult to understand. Hence, controlling it would be difficult and as such upgrading it would be a difficult task too. A suggestion has been made to develop to measure that is, Metric Evaluation for Sustainable University. This metric is developed so that universities can evaluate how far they have practiced the properties of a sustainable university. Furthermore, this metric can be a guide to improve if there are any shortcomings in the properties of sustainability that have not been practiced. This is in line with UTM's efforts in developing Sustainability Index.

Before UTM plans to become a sustainable university, the question would be, "What is actually the meaning of sustainability for a university?". According to Fraenkel \& Wallen [5], no matter how good the environmental performance is in the university, it would be good if we could change our attitude or of an individual to understand the meaning of sustainability in their lives. Therefore, with the existence of the Metric Evaluation for Sustainable University, it is hoped that this evaluation would help the university to come up the properties of sustainable university suitable for UTM. Besides that, this metric can increase the practice of the features of a sustainable university that has not been carried out at UTM. That is, by seeing the program or activity that need to be sustained and how necessary steps can be taken in pursuit of a sustainable university by achieving the highest value through metric evaluation. This metric can also function as supervision in practicing the characteristic of a sustainable university. Features of the metric must be in terms of quality and quantity which is important to evaluate by comparing a process analysis model. The metric should be in line with a few primary aspects such as clarity, in order to interpret the consistent variables which are the sub elements of sustainable university; thus it must be clear,

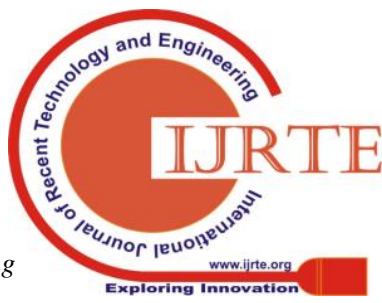


simple and meaningful [11]. According to Rachuri et al. [18], metric needs something that is brief and of high level, and it also needs a good supportive data model. The developed metric must be brief according to the level set. Then, various methodology must be identified to bring the simple metric to higher level, and it must be simple to compare the metric with the standard.

According to Graedel [6], the work process to develop the sustainable metric is by preparing the methodological process scientifically and logically. At the same time, it must match the present situation at the institution.

This is because characteristics of a foreign and local sustainable university may be different and according to their environment in their respective countries. After developing the metric, the university has to plan to take the necessary actions by following a few levels for short term, medium and long term that has been set. This is because they have to carry out the features of sustainable university that can benefit the future generation. In a medium term duration, the parties involve must make their institution green following the scientific model of sustainable university. In long term, the features of sustainable university must be achieved to reach the status of sustainable university.

The development of metric encourages the faculty and administrators in every department to be more strategic in choosing the best to combine the properties of sustainable universities in their programmes and activities that are suitable to the work place. In addition, this metric can prepare a work process for research in the future to see the effect in various properties of sustainable university by collaborating sustainability in their respective universities [20].

According to Graedel [6], the work process to develop the sustainable metric is by preparing the methodological process scientifically and logically. Hence, the development of the metric can help colleges faculties, departments and sustainability and experts to decide on the best alternatives and can make strategic decisions in strenghtning UTM as a sustainable university.

\section{A.Development of Metric Evaluation for Sustainable University}

This Sustainable University Metric Evaluation is developed specially for University of Technology Malaysia (UTM). The aim of developing this metric evaluation is according to Harrington [7] statement about measurement that was discussed in the introduction. The development of this Metric Evaluation is the first step to achieve the aim of a sustainable university. It helps in supervising and contolling every sustainable programme and activity that is carried out in the university. Besides that, it can help the administrators of campus sustainability in planning, comparing and checking to see the level of differences in activities that has been carried out before, now and in future. Finally, it can measure how far UTM has achieved the status of a sustainable university.

\section{B.Basic Structure for Metric Evaluation of Sustainable University}

The metric developed in the earlier chapter is the first draft. It was developed according to the three elements of sustainability that is economy, environment, and social. Each element is then categorized into a few sub-elements with appropriate properties. The characteristics of sustainable university is based on literature research. These characteristics taken from foreign universities, are then suited to to local universities. This can be seen in Diagram 1. The first Metric Evaluation draft was developed before without the opinions and comments of sustainability experts in UTM. Metric Evaluation is also divided into four levels, that is; Level 0 - the lowest, and Level 3 - the highest, used in achieving the sustainable university status. Table 1 shows the four levels used in the developed Metric Evaluation for Sustainable University.

Table 1: Four levels used in Metric Evaluation for Sustainable University

\begin{tabular}{cc}
\hline Score & Level \\
\hline 3 & High \\
& Has carried out consistantly \\
\hline 2 & Average \\
\hline 1 & Has carried out but still in the begining stage \\
\hline 0 & Low \\
\hline
\end{tabular}

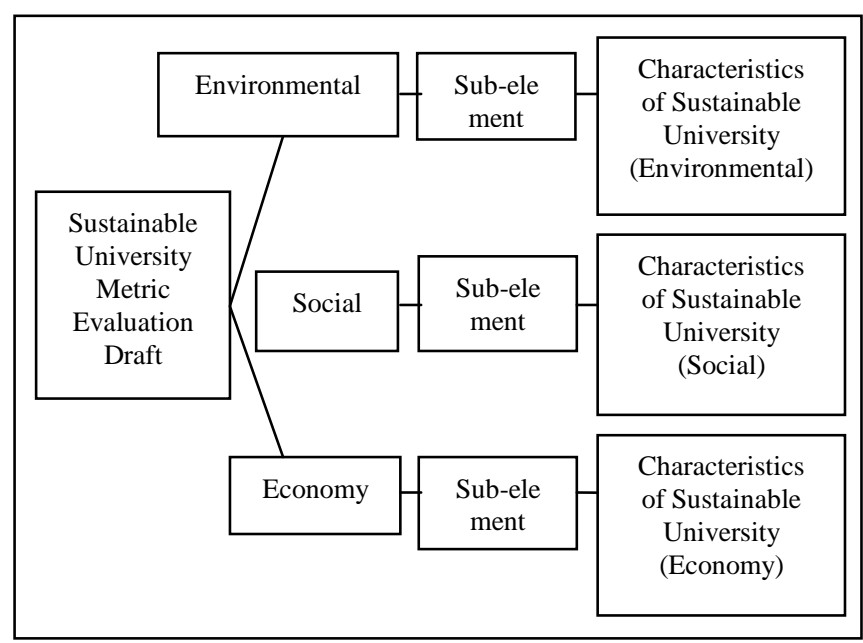

Figure 1 Elements of Metric Evaluation for Sustainable University

\section{The Advantage of the Developed Metric Evaluation for Sustainable University}

This Metric Evaluation is more comprehensive whereby the sub-elements and characteristics of a sustainability used involves all programmes and activities at three levels, that is; the top administrators, academic staff, non-academic and students. Besides that, the development of this Metric Evaluation focuses on the management of sustainable campus that is not only suitable to the present situation at the university but also on future programmes. Some of the characteristics of sustainable university from the Metric Evaluation is according to the sustainable policies and programmes carried out at UTM. Furthermore, the method used is a qualitative method where experts are interviewed in two stages to verify the developed Metric Evaluation. The first stage is to validate the first draft and the second stage is to validate the decond draft. This validation is carried out in two stages as to strengthen the

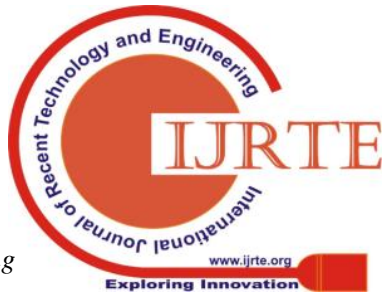


Metric Evaluation so that it can be used to measure the sustainability level at UTM.

\section{METHODOLOGY}

Literature review has been carried out on previous sources that include journals, articles, working papers, theses, books, reports, etc. In general the sources focus on three elements of sustainable development, namely economic, environmental and social. A process is carried out to determine the sub elements that correspond to these three elements. The sub element is determined based on the Sohif et al. [21] with appropriate elements i.e. the elements of the environment related to environmental preservation such as the reduction of waste materials, prevent damage to natural resources and so on.

While the economic elements are related to the costs of expenses and revenue through sustainability such as the reduction of operating costs of energy and water. Finally, the social element is related to awareness, convenience, health in the use of available facilities such as the comfort and health of consumers. Information obtained can support the background of the review and the statement of the problem. In addition, the information obtained will help identify ways on implementation of the characteristics of the evaluation of the sustainable university within a university. To meet these requirements, the information which includes discussion of general functions, education, operations, research and students' activities in UTM, are gathered to develop the assessment level of implementation of the features in the study area.

Secondary data obtained is used to develop the proposed metrics for sustainable university comprising three elements, namely, economic, social and environmental. It is based on the recommendations of the sustainable University metrics by Blackburn [3] used to develop the metrics for the best sustainable features of the University and is adapted to local universities.

The method used in the development of evaluation metrics is by finding a sustainable university's characteristics in terms of performance of environmental, economic and social activities through the literature review. The developed evaluation metrics is in the form of achievement level in accordance with a predetermined score of 0 to 3 to all provided answers. Set scores are based on Badan Akreditasi Nasional Perguruan Tinggi [2], using ' quality grade descriptor',i.e. excellent, good, satisfactory and unsatisfactory. For Sustainable University Evaluation Metrics, qualitative assessment of results is classified as follows:

\section{Score 3 (High) \\ Score 2 (Medium) \\ : Implemented on an ongoing basis \\ Score 1 (Low) \\ : Implemented but still in the early stages \\ Score 0 (Very weak) : Did not implement at all}

Later, the developed metrics must obtain confirmation from the sustainable experts. Sustainable University evaluation metric authentication is done through interviews with experts. The interview is a method with selected experts and involved with the sustainable university for further details on the assessment of the criteria of the metrics in terms of qualifications, accuracy, suitability of the technical aspects and operational metrics.

In this study, an interview will be carried out with respondents to get comments and suggestions to improve the developed metrics. Thus, all the views and recommendations for each sub elements and characteristics of sustainable university on the metrics will be improved.

The verification study is carried out to obtain certification of the metric and to compare the features that have been proposed. External validation study is done with sustainable specialist at Universiti Teknologi Malaysia (UTM). It is implemented to improve, and get validation as well as approval of the proposed metric of sustainable university through economic, social and environmental.

Comments from experts on the metric will be used to improve the metrics for future development. This verification is very strongly emphasised in the study for the expansion of the method in other places [22]. Verification from experts is only carried out at UTM with 13 men out of 15 experts.

According to Patton [17], there are no rules in sample size of qualitative (expert interview). Meanwhile Zikmund [25] states that a large sample size can obtain more accurate results of the study. Based on Wiersma \& Jurs [23], small sample size also can produce study that highly trusted because the sample chosen can represent the population study. A sample of 'judgment sampling' or also known as 'purposeful sample', which is commonly used sampling techniques were selected for study being conducted. According to Marshall [9], this sample was selected based on evaluation research that respondent is the most suitable respondent to be made sample in the study. This involves a framework developed in which it can contribute to an individual. It developed based on to researcher knowledge in study carried out itself from the study of literature and available evidence. It is an intellectual sample named 'key informant sample' because it is based on knowledge and skilled highly in particular field. In making the interpretation of the data, it is important to consider the subject (the experts), those who support the explanation (whether the samples confirmed and not confirmed).

Meanwhile, according to Ross [19], the process of 'judgement sampling' is based on researcher assumption that chooses suitable elements for targeted population to represent 'typical sample'. This is because not both experts that will agree to alter a thing to become more accurate in 'typical sample'. Therefore, if there is no influence of external criteria, hence there is no other way to obtain the results of the study from 'judgment sample' than others to assess more accurately. For example, researchers interviewed respondent $\mathrm{A}$ and respondent $\mathrm{B}$. Both respondents may have different views, and finally the researcher will make a reasonable inference to confirm a study.

\section{A. Interviews with Experts}

The sample method was chosen because of its advantage, as it is simple, less costly and the revenue data is suitable for the specified respondents [8]. Some of the experts interviewed are participants who had joined the UTM Sustainable Canpus Strategic Workshop Pelestarian UTM Campus. Respondents were selected based on their own expertise in the field of sustainability. During the workshop they were divided 
and given tasks according to these three elements, namely, the environment, social and economic.

Thus, making it easier for researchers to carry out the study through interviews on the revision and verification of the developed metrics according to the elements of sustainability. The chosen sustainable experts selected consists of those involved in the Sustainability Technical Committee in UTM. A study is done to collect data from the sustainablility experts. The developed evaluation metrics from the literature review is distributed to the sustainable experts for revision.

Then, an interview is conducted to obtain data on the views of experts about the overall metrics Based on Marshall \& Rossman [10], interview is the easiest technique to get a lot of contextual and indepth data,to get background information on more focused activity, behavior and other things about the respondent and to secure the cooperation of the subject of study in a natural manner. The items of the interviews can also be added from time to time to obtain the required information. In this study, interviews focus on the appropriateness of the developed evaluation metric of sustainable university and to obtain certification from the sustainability experts. The interview respondents are sustainability experts as they are exposed to many challenges and roles as they reflect the style of leadership in implementing sustainable features at UTM. The interview methods used are face to face interviews with sustainability experts. According to Mohamad Najib [13], this method makes it easier to get feedback and detailed explanation from the interviewers. The data obtained from this interview is very reliable. According to Mohd Majid [14], these methods indirectly assist researchers to gather new information that cannot be obtained from reading materials. Interviews with experts are carried out twice to get confirmation on the metrics developed. The first interview question is about the advantages, disadvantages and improvement for the developed evaluation metrics. The second interview question is about the appropriateness, limitations and improvement.

The purpose of the first interview question is to check the developed evaluation metrics. It will also gather new data if any of the sustainable university characteristics not listed. This will indirectly make improvement to the metrics, should there be appropriate comments and suggestions by the respondent. The second interview question is to review the metric that has been improved. Next improvement is done again if there are comments and suggestions given by the expert. Finally, Metric evaluation of Sustainable University is developed for UTM after improving the previous Metric evaluation.

\section{B. The Reliability And Validity Data}

Study of validity and legitimacy are instruments that ensure accuracy in a questionnaire. According to the 'American Psychological Association' the definition of the validity is accuracy, truthfulness, meaningfulness and usability of the instrument so that conclusions on the data can be made on facts. The technique used to validate the data for this study is 'Content-Related Evidence of Validity'. According to Fraenkel \& Wallen [5], this technique was to prove the accuracy of the contents of the items while assessing the instrument by a group of experts, This means the accuracy of the content, comprehensive nature of the instruments and the use of variables can help the experts to understand in order to evaluate it. Through the definition of validity by American
Educational Research Association et al. [1], the purpose of this study is to verify the instrument so that it can be defended (the results are accurate and useful), accuracy (answers the study questions), appropriateness (relevant to the purpose of the study), meaningful (gives meaning to the data through the score) and usability (able to make the decisions sought or generated). The study is refered to the experts to check the authentication forms of the developed evaluation metrics and reliability of the form. The reliability is obtain through interview. According to Fong [4], the degree of reliability can be increased by making repeated interviews with the same experts by asking questions that are very necessary. Thus, repeated interviews, with the same experts in the first stage, are carried out at the second stage of this study. According to Merton \& Kandall [12], an effective interview is when the data obtained is reliable and valid.

In carrying out this study, a voice recorder is used for recording the interviews with experts in person to analyze the reliability of the data. Eventually, certification of the experts is obtained through the distribution of metric evaluation of sustainable university form.

\section{FINDINGS OF THE STUDY}

\section{A.Sustainable University Metrics Evaluation}

Through the study, the sustainable university evaluation metrics was developed based on the comments and recommendations made by the experts. Figure 3 shows a part of the sustainable university evaluation metrics according to the element, sub elements and features that were developed after the improvements for the second time. This evaluation consists of three categories according to the elements of sustainability. These categories are then divided into sub elements, namely; the environmental category which consists of 24 sub elements, the social category is made up of 22 sub elements and the economic category consists of $9 \mathrm{sub}$ elements. Finally, the sub elements are divided into characteristics of the sustainable university. Among the characteristics of sustainable university are; the environment element are made up of 80 features, the social element consists of 115 features, and the economic element comprises 29 features. According to Sohif et al. [21], the sub elements are specified in accordance with the evaluation metrics that will be developed according to the current situation.

Environmental elements are related to environmental preservation such as the reduction of waste materials, prevent damage to natural resources and etc. The social element is related to the awareness, convenience, and health when using the facilities provided such as the comfort and health consumers.

The economic elements are related to the costs of expenses and the revenue through sustainability such as the reduction of operating costs of energy and water. The sub elements are developed in the aspects of education, operations, research and students' activities at UTM to develop the evaluation to gauge the level of implementation of the features in the study area.

The sub elements and characteristics of sustainable university are obtained based on authentic sources that are to be used for the development of this metric evaluation.

After developing the sustainable university 
evaluation metrics, sustainability experts have stated that the evaluation metrics can help the universities achieve a sustainable campus. This will enable the university to see the gaps between the present sustainable program with a sustainable program that the university should have adopted, as a basis for planning the university's sustainability in the future. Economically, it will summarize the effectiveness and financial efficiency as well as a step for improvement. Socially, it is holistic in nature and the assessment covers all aspects of sustainability and spirituality.

\section{B.Future Research Suggestion}

Given that the sustainable university evaluation metric developed is only in UTM, further studies can be carried out by comparing it with other universities by including other Institutions of Higher Learning (IPTA). This aims to develop further the existing characteristics of sustainable universities to overcome deficiencies in these valuation metrics.

The next research suggestion is to improve the metric by using percentages, per capita, standards and evaluation units in quantitative form. The description of the features can be further distinguished if they are used in standard form units. This is aimed at facilitating the use of metrics in the evaluation and comparison of the future.

Lastly, the research suggestion is to develop more detailed university characteristics at every level, such as student residences, faculties, and departments. This is to ensure that the characteristics of sustainable university that will be developed can be used at all levels of the university. As the metrics in this study focus more on management and administration level.

\section{Impact of Study}

The evaluation metrics developed to bring benefits, especially to UTM. Sustainable experts have stated that these metrics can be used as planning and directions for future use. Characteristics that are not implemented in UTM can be used as additional information to achieve sustainable university status. It can also be used for monitoring purposes to assist in the overall process in sustainability universities. Furthermore, this metric was developed with the involvement of all levels of higher authorities, academic staff, non-academic staff and students. It aims to help the parties involved to manage sustainability more systematically. This enables the university community commitment to implementing sustainable university.

\section{CONCLUSION}

The development of the sustainable university metric evaluation is a measurement tool based on the management and sustainability strategy of the campus implemented at the university. This measurement is one of the initial steps for those involved in sustainability to learn the characteristics of sustainable university. This evaluation metrics is used as a guide and assessment to monitor if UTM or other universities have already implement or not the sustainable university features. These features are important in improving the quality of the life of the university community as well as to preserve the environment continuously. The sustainable university features in relation to the concept of sustainable development is taken into account through a number of aspects, such as community, operations, administration, education and research. These aspects are emphasized to transform the local universities to sustainable university. The sustainable university features are set based on its suitability in Malaysia and especially for UTM.

\section{ACKNOWLEDGMENT}

I would like to express my deep gratitude to Assoc. Prof. Sr. Dr Choong, my research supervisors, for their patient guidance, enthusiastic encouragement and useful critiques of this research work. Special thanks should be given to Assoc. Prof. Dr. Khatijah for her professional guidance and valuable support. I would also like to thank the all UTM sustainable experts for their participation in the interview who supported my research in this way and helped me get results of better quality.

\section{REFERENCES}

[1] American Educational Research Association, American Psychologica Association, \& National Council on Measurement in Education. 1985. Standards for Educational and Psychological Testing. Washington, DC: American Psychological Association.

[2] Badan Akreditasi Nasional Perguruan Tinggi. 2010. Akreditas Program Studi Doktor. (Edition 7 January 2010). Jakarta: BAN-PT.

[3] Blackburn, W. R. 2007. The Sustainability Handbook. UK \& USA: Earthscan. 2007

[4] Fong M. L. 1981. Evaluating Validity and Reliability of Selected Qualitative Research Methods. Singapore: National University of Singapore.

[5] Fraenkel, J. R. and Wallen, N. E. 1996. How to Design and Evaluate Research. Mc. Fraw-Hill Inc.: USA.

[6] Graedel, T. E. 2002. Quantitative Sustainability in a College or University Setting. International Journal of Sustainability in Higher Education. 3(4): 346-358

[7] Harrington, H. J. 2005. Performance Measure Quotations http://-corpslakes.usace.army.mil/-employees/perform/quotes.cfm. Accessed on February 25, 2011.

[8] Lesser, V. M. 2011. Advantages and Disadvantages of Probability and Nonprobability Based Surveys of the Elderly and Disabled. National Center for Accessible Transportation. Oregon State University (OSU). http://ncat.oregonstate.edu/pubs/TRANSED/-1081_Surveys.pdf. Accessed on Oktober 12, 2011.

[9] Marshall, M. N. 1996. Sampling for Qualitative Research. Family Practie. Oxford University Press 1996. 13(6): 522-525.

[10] Marshall, C., Rossman, G. B. 2006. Designing Qualitative Research. 4th ed. London: Sage Publications.

[11] Martins, A. A., Mata, T. M., Costa, C. A. V. 2007. Framework for Sustainability Metrics. Industrial and Engineering Chemistry Research. 46(10): 2962- 2973

[12] Merton, K. and Kandall, P. 1946. The Focussed Interview. American Journal of Sociology, vol 51., Nos 1-6., July 1945 - May 1946, Chicago, Illinois: University of Chicago.

[13] Mohamad Najib Abdul Ghafar. 1999. Penyelidikan Pendidikan. Skudai: Universiti Teknologi Malaysia Press.

[14] Mohd Majid Konting. 2000. Kaedah Penyelidikan Pendidikan. Kuala Lumpur: Dewan Bahasa dan Pustaka.

[15] Naoum, S. 2007. Dissertation Research \& Writing for Construction Students. $2^{\text {nd }}$ ed. Oxford: Butterworth-Heinemann.

[16] Neuman, W. L. 2006. Social Research Method: Qualitative and Quantitative Approaches. 6th. ed. Boston: Pearson.

[17] Patton, M. Q. 2002. Qualitative Research and Evaluation Methods. 3rd Ed. London: Sage Publications. 2002.

[18] Rachuri, S., Sriram, R. D., Narayanan, A., Sarkar, P., Lee, J. H., Lyons, K. W., Kemmerer, S. J. 2010. Sustainable Manufacturing: Metrics, Standards and Infrastructure- Workshop Summary. Proceeding of the 6th Annual IEEE Conference on Automation Science and Engineering, August 21-24, 2010. Marriott Eaton Centre Hotel. Toronto, Ontario, Canada. 2010. 144-149.

[19]Ross, K. N. 1987. Sample design. International Journal of Educational Research. 11(1): 57-75. 
[20] Rusinko, C. A. 2010. Integrating Sustainability in Higher Education: A Generic Matrix. International Journal of Sustainability in Higher Education. 11(3): 250 - 259.

[21] Sohif Mat, Kamaruzzaman Sopian, Mazlin Mokhtar, Baharuddin Ali, Halimaton Saadiah Hashim, Abdul Khalim Abdul Rashid, Muhammad Fauzi Mohd Zain, Nurakmal Goh Abdullah. 2009. Managing Sustainable Campus in Malaysia - Organisational Approach and Measures. European ournal of Social Sciences. 8(2): 201- 214

[22] Stewart, D. W., Shamdasani, P. N., Rook, D. W. 2007. Focus Group: Theory and Practice. 2nd ed. Thousang Oaks: Sage Publications.

[23] Wiersma, W., Jurs, S. G. 2005. Research Methods in Education: An Introduction. 8th. Ed. Boston: Allyn \& Bacon.

[24] Zaini Ujang. 2009. Minda Lestari. Skudai: Penerbit UTM Press

[25] Zikmund, W. G. 2003. Business Research Methods. 7th ed. Thomson/South-Western: Cincinnati, $\mathrm{OH}$. 